\title{
MOBILIDADE E FIXIDEZ DE UMA POESIA EM TRÂNSITO
}

Fabiane Renata BORSATO ${ }^{120}$

MARTINS, A. Em trânsito. São Paulo: Companhia das Letras, 2010.

O desenho de capa minimalista de Kiko Farkas para a obra Em trânsito compõese de linhas pretas sobre fundo azul e registra diferentes marcas verticalizadas e ziguezagueantes que, ambiguamente, também se fazem vista superior de sinais advindos de um provável rolamento do objeto em fluxo quase contínuo. Interrupções do traçado são notáveis na parte superior da capa, tanto na primeira quanto na terceira marcas, sendo que a central é interrompida no canto inferior da capa, talvez cesuras representativas dos versos que se encontrarão no livro. As marcas transitam paralelisticamente, em linhas de espessura diversa, organizadas no azul-mar do fundosolo. As elipses das marcas também sugerem o ir e vir do objeto ausente, presentificado pelo rastro que deixa no fundo azul. A dinâmica indica aspectualidade durativa do evento nos sinais da ação e na retirada de cena do objeto responsável por ela.

O título da obra Em trânsito sustenta-se na ação em devir, sugerida pela capa de Farkas. O poema homônimo que encerra o livro anuncia um eu poético em primeira pessoa e em trânsito: a caminho do trabalho, entre automóveis, estações de trens, plataformas, pontes, rios. $\mathrm{O}$ ir e vir dos eus poéticos é intercalado pelas paradas reflexivas, formas coerentes com o fluxo quase contínuo e as elipses do desenho de capa. Entre ações mecânicas, encontramos reflexões líricas como a dos versos finais do poema em questão: "ainda não fiz cinquenta anos/ dá tempo de mudar alguma coisa." (MARTINS, 2010, p.109 ${ }^{121}$ ) que surge como intenção de dar cessação ao evento exposto

120 Departamento de Literatura. Programa de Pós-Graduação em Estudos Literários. Faculdade de Ciências e Letras, Universidade Estadual Paulista, UNESP, campus de Araraquara, CEP 14800-901, Araraquara, SP, Brasil - fabiane $@$,fclar.unesp.br

121 Devido ao grande número de citações de excertos de poemas da obra Em trânsito presente na resenha em questão, informamos que, em favor do fluir da leitura, omitiremos autor e ano para identificarmos somente a paginação entre parênteses, sendo que a edição usada como referência é a de 2010. 
na estrofe anterior e sua semântica da reiteração de ações mecânicas e rotineiras: "vou tomar esse trem/ pela última/ primeira/ vez" (p.109).

Entre movimentos contínuos e paradas reflexivas, os eus poéticos constroem os versos de Em trânsito, obra de Alberto Martins, artista que empreende trajetória por diversos gêneros e artes, como poesia, narrativa, teatro, xilogravura, escultura, além da literatura infanto-juvenil. Enquanto em Cais (2002), Alberto Martins deslocava o olhar dos enunciadores por espaços marítimos e metalinguísticos; na obra Em trânsito, o espaço faz-se urbano e prevalece a marca do artista na presença do olhar móvel dos enunciadores e na apreensão das coisas e fatos de variáveis e inusitados pontos de vista.

Em trânsito estrutura-se em três partes antecipadas por um poema dedicatória, à maneira de prólogo, intitulado "Este livro é para o leitor", revelador da tendência adjetiva do texto, ao descrever o leitor como atônito, normal, anônimo e comum, a quem é destinada a obra. Na orelha do livro, Chico Alvim menciona a relação da obra com o real, "travessia de um homem comum, na verdade o leitor e seu duplo, o poeta...". O flanêur baudelaireano, os passantes que circulam pelas cidades, a memória refrativa e íntegra ganham síntese e contenção nessa obra.

As três partes apresentam certa unidade e um movimento contínuo que sofre interrupção na parte central. Isso quer dizer que enquanto as duas partes de abertura e encerramento da obra apresentam cinesia explícita no título e no tema empreendido: "A caminho do trabalho" e "Em trânsito", a parte central aborda as "Inscrições" e apresenta os semas da fixidez, da permanência, da consagração da memória e do tempo, do resguardo da história e dos fatos. O equilíbrio e a coesão entre as partes também é notável pela simétrica quantidade de poemas, sendo $23 \mathrm{em}$ cada uma das duas primeiras partes e 24 poemas na parte final, sendo que o poema de encerramento da obra surge à maneira de posfácio que retoma a questão do trânsito rumo ao trabalho, cuja rotina é surpreendida pela urgência da mudança de trajeto.

A primeira parte, "A caminho do trabalho", descreve cenas e a relação sutil e impessoal de implicação entre observador e observado. "Transeunte" e "Outro transeunte" revelam marcas líricas nas interrogações e nos enjambements que separam não só palavras, mas sílabas: “-papel rasgado bi/ tuca de cigarro tam/ pinha de plástico -“ (p. 14). A relação de implicação entre os poemas dá-se pela afirmação de marcas e ecos deixados pelo transeunte, no ato de transitar, que funcionam como memória ou sobreposição de passos que apagam a pessoalidade, questão evidenciada no 
enjambement que provoca uma "desconexão entre o elemento métrico e o elemento sintático, entre o ritmo sonoro e o sentido." (AGAMBEN, 1999, p.32).

Há ainda que considerar a diversidade rítmica dos poemas, construídos por versos de uma a dezesseis sílabas métricas e esquemas rítmicos variados, próximos da prosa: “- se você não escreveu nenhum livro/ como pode viver de literatura?- " (p.43). A oralidade desses versos reflete o traço prosaico dos poemas e sua forte aproximação da linguagem falada e coloquial.

A monotonia é aspecto importante da primeira parte do livro. No longo poema de cinco partes, "Vira-lata na madrugada", o enunciador compõe cenas noturnas advindas do latir incessante de um cão. Os 50 tercetos apresentam repetições de estrofes e palavras, além de versos curtos baseados em permutas e paralelismos sintáticos e morfológicos, recursos geradores da monotonia do latido contínuo do cão a sonorizar a noite e o sonho do eu poético. O cão solitário na noite, pela insistência de seu latido e de suas ações ruidosas, gradativamente habita "toda a madrugada" (p.27). Espaço, tempo, som e imagem unem a dor do cão ao sonho do homem, espaços de fantasia e realidade.

Os textos da primeira parte apresentam paisagens urbanas percorridas por observadores ora em movimento, ora à espera de meios de locomoção ou envoltos em ações particulares. Predominam espaços e cenas noturnas e opressoras. Apartamentos cubiformes ou os metrôs catacumbas de "Working day" informam que luz e céus azuis são lugares intersticiais em que o sujeito não permanece porque ao sair dos túneis do metrô entra em elevadores, trens e apartamentos, espaços fechados e impessoais onde ocorrem e cenas possíveis e impossíveis de se tornarem poesia. Contrastantes cenários são aliados a frequentes interrogações reveladoras do desconhecimento do outro que, apesar de próximo espacialmente, faz-se distante e anônimo, nas múltiplas facetas da cidade: “- será outra a cidade?// no Butantã/ no Jaraguá/ na Leopoldina// “- será outra a cidade?// ou a luz desta janela/ também se faz/ vista de lá?’(p.22).

O encontro entre sujeitos é, portanto, escasso, fato ocorrido "em alguns momentos" (p.17) ou quando o caminhar faz-se paralelo, "abraçados/ aos pacotes de leite \& pão" (p.18). A onisciência sobre a moça transeunte do poema "Xadrez no centro" surpreende. O enunciador observa a moça "indecisa/ entre a banca de jornais/ e o garoto que vende bilhetes de metrô", descreve-lhe o gestual e na estrofe final revela um saber existencial sobre o outro: "ela sabe/ que cada passo é um erro cada passo/ é um logro - mas quem não joga/ perde a vez e nunca mais/ volta pro jogo” (p.33). Essa proximidade de enunciador e sujeito descrito não é freqüente na obra Em Trânsito, mas 
quando se trata do sujeito moça, há recorrência dessa perspectiva aproximativa, o que pode ser notado no poema "O ladrão e a moça" em que o eu poético explicita sua perplexidade diante da beleza da moça "que nos atinge/ sem como/ nem por quê" (p.34)

A segunda parte da obra, "Inscrições", remonta a origens arqueológicas e a questões de registro, memória, sincronia e diacronia. As mais diversas formas de inscrição oferecem aos poemas a possibilidade da prática de variações em torno de um mesmo tema da história e da memória, aspecto anteriormente presente na ressignificação histórica de Cais. Luzia, a mulher mais antiga da América, é sujeito do primeiro poema. Descobertos seus ossos em cacos, o eu poético a interroga sobre a dor sentida e volta temporalmente há onze mil e quinhentos anos para dar humanidade ao achado arqueológico.

A comunhão de tempos e sujeitos distantes também é tema dos poemas " $\mathrm{Na}$ padaria com Flávio Di Giorgi" e "Tipografia”. No primeiro poema há o encontro, por meio da poesia, de Horácio e Flávio Di Giorgi, reunindo sujeitos distantes entre si dois mil anos. O poema "Tipografia" dá voz ao eu lírico em primeira pessoa, disposto a empreender viagem - imaginativa? fantasiosa? - rumo à cidade inundada pela represa de Três Gargantas, às margens do rio Yang Tse. Os 375 tipos chineses armazenados numa caixa de madeira serão o objeto desencadeador da união de histórias, sujeitos e tempos.

Uma série de inscrições revisitadas pelos enunciadores são ressignificadas pela aproximação do universal com o particular: “A história é antiga/ Remonta a vários antepassados:/ todos temos a queixada forte." (p.50). Inscrições testamentais; preservadas em museus; postas em cartas; gravadas nas paredes das grutas, na madeira, na pedra, no papel, nas fotos de Rodchenko e Robert Capa, nos livros, nos poemas, no mito dão voz aos antepassados, identificando-se com suas dores, condição e mortalidade, aspectos recorrentes nessa parte da obra. A passagem da condição vital de existência para a morte é narrada a partir da transformação humana em ossos arqueológicos, do uso do sangue como fluido para inscrição nas rochas, da permanência de deuses inscritos em pedras, ossos, madeiras.

O mecenato e as relações entre autor e público são discutidos nos poemas "Fragmento", "Segundo Plínio, o Velho" e "Carta de Albrecht Dürer (1471-1528) ao conselho de Nuremberg em 1526" que mencionam a função social, moral e mecênica da arte. Por outro lado, inscrições anônimas dos primeiros impressores da península ibérica remetem ao momento em que a função autor era desimportante, em que a historicidade ainda não entrara em voga e as obras podiam sair “de mãos desconhecidas” (p.67). 
O sujeito em contínuo trânsito por espaços diversos da primeira parte, aqui é deslocado para a descontinuidade de um tempo histórico e mítico, simultaneamente móvel e fixo, capaz de comungar sujeitos e épocas diversas. Trata-se de uma ruptura do devir desprovido de sentido e de poesia para a apreensão de outras existências e aprendizado da dor da criação. Após essa pausa reflexiva haverá, na última parte intitulada "Em trânsito", o retorno ao contínuo da existência trivial e cotidiana, lugar em que um número considerável de poemas enuncia o trabalho e a dinâmica espacial urbana como fatores responsáveis pelo ritmo das coisas e dos sujeitos.

Sujeitos do fazer, tais como os trabalhadores, o poeta e o leitor "que por uma questão de espaço/ chega sempre atrasado/ aos últimos lançamentos" (p.9), veem-se a mercê de leis que paralisam o trabalho e de um trânsito caótico que manipula pessoas e coisas: "de repente as coisas avançam/ de repente/ ficam como estão" (p.97), todos sujeitos ao sabor ou dissabor das circunstâncias sociais, políticas, econômicas e especialmente trabalhistas. Este espaço crítico, reservado à terceira parte, ainda poetiza o "Povo errante", metaforizado na figura do menino chamado Moisés que "empurra/ duas balas por um real." (p. 101), enquanto o sinal permanece fechado. Trata-se de microcosmos representativos de uma situação urbana mundial de pobreza, relações impessoais, produção e consumo desenfreados, fatores que aprisionam o sujeito em condições dolorosas de existência e que o habituam à dor e à ausência de autonomia e liberdade, condição similar à do vira-lata do poema homônimo, em quem o eu poético reconhece um olhar fundo, "mais fundo que um irmão" (p.83). Cão que finge não sentir a dor da corrente de metal atada ao pescoço.

Outro traço recorrente na parte três é a presença de relações sinedóquicas e metonímicas. Há o enunciador que, em sonho, concebe metades das casas, enquanto a outra metade construída se incendeia continuamente (p.105), há sacolas "vazias/ de todo conteúdo" (p.81) e a compra de sacos de lixo porque "Existe mesmo muita sujeira por aí." (p.82), indícios da incompletude da existência do sujeito. Esvaziado de substância, o existir do sujeito é fragmentado e incoerente tal qual a relação da velha fechadura com as chaves, nos versos de "Inutilidades domésticas": "joguei no lixo/ a velha fechadura/ (...) as portas/ que ela trancou/ e abriu/ (...) agora são - lembranças// só as chaves não sabem/ e vagam pela casa/ de gaveta em gaveta." (p.85). A ruptura da relação de implicação entre chave e fechadura, das relações entre presente e passado, velho e novo, memória e fato indicam a complexidade dos versos de um poeta que parte do concreto, muitas vezes banal, para desencadear reflexões filosóficas e existenciais. A 
incompletude do sujeito e as perturbações existenciais adquirem possível solução no poema "O trânsfuga", parte 3, momento em que o eu poético propõe "cavar um buraco/ abrir um túnel” (p.106), devido à urgência de uma "outra geografia" (p.106), comungando com o pedido de urgente mudança do dístico de encerramento da obra, mencionado no início da resenha: "ainda não fiz cinquenta anos/ dá tempo de mudar alguma coisa.” (p.109). A possível mudança de quem está em trânsito abre um leque de alternativas para uma poesia que se faz da combinação rítmica e sintática de palavras empregadas no limite da prosa, entre dinâmicas de sucessividade de sujeitos em trânsito entre presente e passado e de necessárias paradas reflexivas e transformadoras.

\section{REFERÊNCIAS}

AGAMBEN, G. Ideia da prosa. In . Ideia da prosa. Tradução, prefácio e notas de João Barrento. Lisboa: Cotovia, 1999. p.30-33.

MARTINS, A. Em trânsito. São Paulo: Companhia das Letras, 2010. 